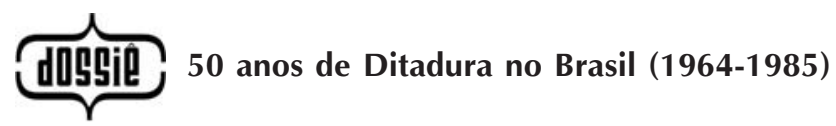

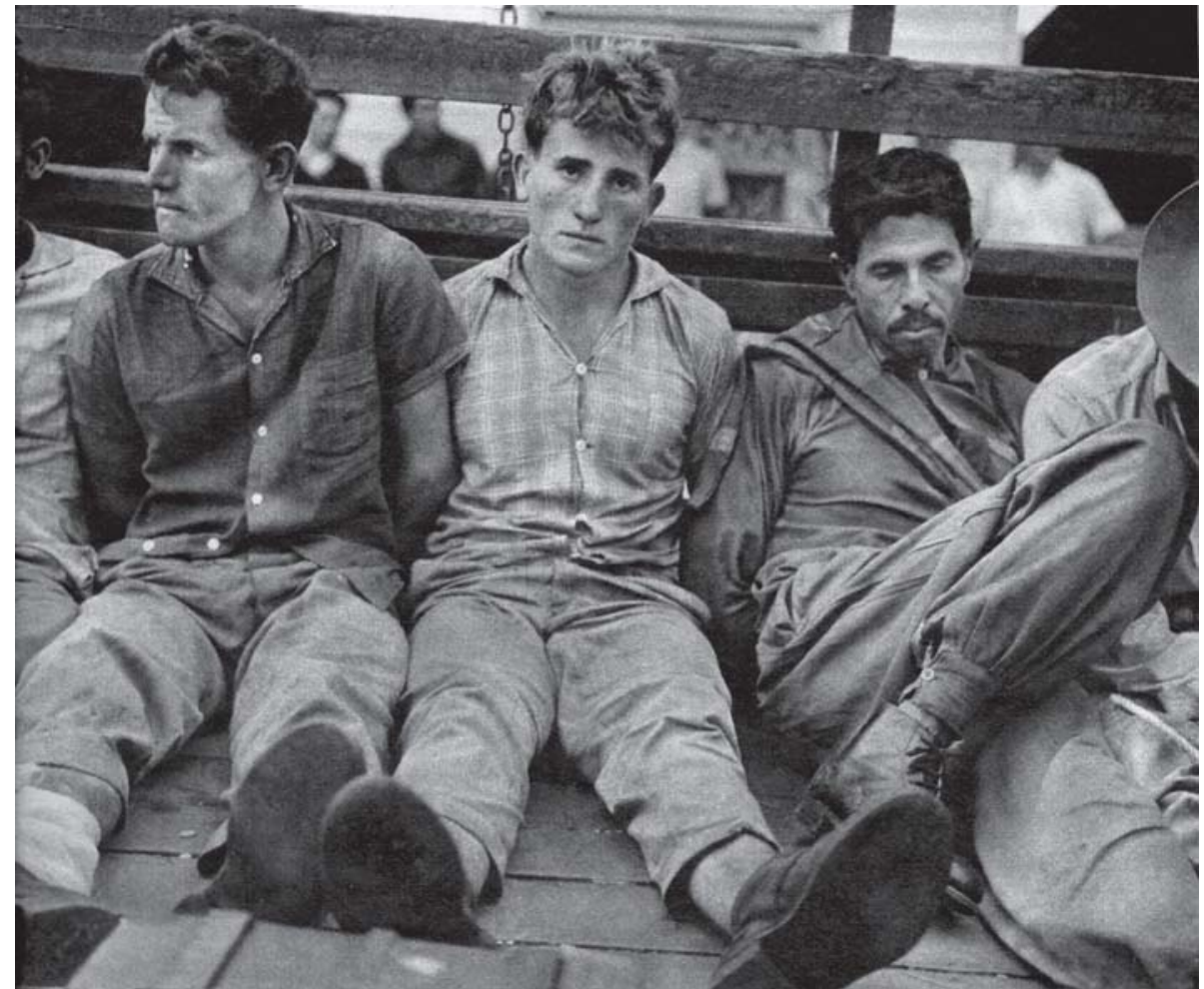

Memórias reveladas - Guerrilheiros participantes da Guerrilha de Três Passos, presos no sul do país pelas forças do governo. Data: 1965. Arquivo Público Mineiro (APM) 


\title{
Memórias Reveladas: justiça de transição e o sombrio legado da ditadura militar
}

\author{
Memórias Reveladas: transitional justice and the gloomy \\ legacy of the Brazilian military dictatorship
}

\section{Inez Stampa*, Vicente Rodrigues**}

\begin{abstract}
Resumo- $O$ presente artigo tem por objetivo discutir a criação e o desenvolvimento do Centro de Referência das Lutas Políticas no Brasil (1964-1985) - Memórias Reveladas, iniciativa voltada para a proteção e difusão do patrimônio documental brasileiro do período da ditadura militar. Visando contribuir para o debate sobre a justiça de transição no Brasil, identifica as peculiaridades que conformam a experiência brasileira, definindo a justiça de transição como um novo campo de estudo e ação que tem por objetivo o enfrentamento de legados repressivos. Traça um panorama do acervo brasileiro da repressão, discute recentes alterações na regulamentação do acesso público a esses documentos, centrando-se numa reflexão sobre o papel desempenhado pelo Memórias Reveladas e sua articulação com duas outras ferramentas de justiça de transição recentemente criadas, a Comissão Nacional da Verdade e da Lei de Acesso às Informações.

Palavras-chave: Memórias Reveladas; ditadura militar; Comissão Nacional da Verdade; Lei de Acesso às Informações.
\end{abstract}

\begin{abstract}
This article aims to contribute to debate the creation and development of the Reference Center of Political Struggles in Brazil (1964-1985) - Revealed Memories, an initiative that seeks to protect and to diffuse Brazilian public documents heritage from the period of military dictatorship. In order to contribute to the debate about the Brazilian transitional justice, identifies the peculiarities that make the Brazilian experience, defining transitional justice as a new field of study and action that aims to con front the regressive legacy. It draws a panorama of the Brazilian archives from the repression period, debates some legal changes in its public accessibility, focusing on a reflection on the role of Memories Revealed and its relationship with two other tools of transitional justice recently created the National Commission for Truth and the Law on Access to Information.

Keywords: Revealed Memory (Memórias Reveladas); Brazilian dictatorship; Brazilian National Commission for Truth; Law on Access to Information
\end{abstract}

\footnotetext{
* Graduada em Ciências Sociais e em Serviço Social pela UERJ, é doutora em Serviço Social pela PUC-Rio, onde é professora do Departamento de Serviço Social com inserção na graduação e na pós-graduação. É servidora do Arquivo Nacional, atuando na coordenação do Centro de Referência das Lutas Políticas no Brasil (1964-1985) - Memórias Reveladas. Correspondência: Rua Dr. Satamini, 105, ap. 301 - Tijuca - Rio de Janeiro - RJ. CEP: 20270-232. E-mail: < inestampa@ig.com.br>

** Graduado em Direito pela UFRJ, é mestrando no Programa de Pós-Graduação em Direito da UFRJ e membro do grupo de pesquisa do CNPq Trabalhadores e Ditadura Civil-Militar no Brasil, da PUC-Rio. Assessor da direção-geral do Arquivo Nacional para o Centro de Referência das Lutas Políticas no Brasil (1964-1985) - Memórias Reveladas. Correspondência: Rua Dr. Satamini, 105, ap. 301 - Tijuca - Rio de Janeiro - RJ. CEP: 20270-232. E-mail: < vicenteacr@ yahoo.com.br>
} 


\section{Notas introdutórias}

Passados cinquenta anos do Golpe de Estado de 1964, e pouco menos de três décadas do fim do último governo militar brasileiro, o debate público sobre os direitos humanos ${ }^{1}$, no Brasil, experimenta um momento singular e estimulante, com a crescente pressão da sociedade civil visando ao esclarecimento de casos de graves violações de direitos humanos e por maior transparência pública² .

Contudo, persiste, ainda, a necessidade de reforçar o entendimento coletivo de que o período da ditadura militar, que vai de $1^{\circ}$ de abril de 1964 a 15 de março de 1985, foi marcado, na história política e social brasileira, por violações sistemáticas de direitos humanos - inclusive assassinatos, desaparecimentos forçados e pela prática da tortura por motivos políticos -, bem como pela negação de valores democráticos e pelo arbítrio do Estado. De acordo com pesquisa publicada, em março de 2014, pelo Datafolha, para $16 \%$ da população brasileira tanto faz se o governo é democrático ou uma ditadura, $14 \%$ defendem que em certas circunstâncias é melhor uma ditadura do que um regime democrático, e $8 \%$ que não souberam responder (DATAFOLHA, 2014).

Neste ponto, cabe destacar que parte da historiografia nacional refere-se à caracterização do golpe, e da própria ditadura, como "civilmilitar" e não, apenas, "militar". Conforme defende Silva (2003, p. 271), é preciso considerar, na caracterização do regime, as "íntimas e complementares relações entre empresários e militares na conspiração contra o regime constitucional no Brasil". Neste artigo, contudo, optou-se por manter a expressão "ditadura militar", por entendermos que o caráter militar foi preponderante na estrutura estatal do regime, embora a estreita vinculação com a sociedade civil seja considerada fundamental para a contextualização e compreensão do período.

O quadro de desconhecimento ou negação dos valores democráticos, associado à não responsabilização de perpetradores de violações de direitos humanos, traz impactos diretos para a atuação dos órgãos de segurança, como é evidenciado pelo fato de que a polícia brasileira mata mais e comete mais abusos hoje do que no período da ditadura, conforme reconhecido pelo próprio governo federal (SECRETARIA DE DIREITOS HUMANOS/PR, 2010, p. 37). Assim, sem memória e sem justiça, reproduzemse e multiplicam-se práticas, usos e costumes lastreados na impunidade e no esquecimento.

Nesse contexto, a adoção de políticas específicas de memória para enfrentar esse passado está no centro da chamada "justiça de transição",

\footnotetext{
${ }^{1}$ A expressão "direitos humanos" é aqui compreendida, de forma geral, como um grupo de direitos historicamente construídos que têm como destinatários todos os seres humanos. Isto é, representa posições jurídicas ativas de direitos comuns a todas as pessoas, pelo simples fato de serem humanas (COMPARATO, 2010).

${ }^{2}$ Exemplo disso foi a criação da Comissão Nacional da Verdade, em 2011, mas cujas atividades se iniciaram apenas em 2012, e a entrada em vigor da nova Lei de Acesso às informações (Lei 12.527, de 18/11/2011). (BRASIL, 2011).
} 


\section{ReVistg all paUtg}

\} MEMÓRIAS REVELADAS - STAMPA, I.; RODRIGUES, V.\}

cujo conceito será abordado mais adiante. Por ora, cabe lembrar que a justiça de transição tem por função não somente garantir o entendimento do que ocorreu, mas, também, reforçar a compreensão de que não é possível a um povo (re)conhecer a si próprio sem entender o legado de sua história política e social. Nesse processo, as iniciativas voltadas para a recuperação e difusão de informações contidas nos arquivos da repressão e da resistência assumem posição de destaque, em meio a tensões e disputas pela memória.

Defender que a memória é um bem público não significa deixar de reconhecer que ela mesma é resultado dos contextos e dos agentes que a constroem (CARBONARI, 2010). Assim, a memória pode ser apropriada e transformada para cumprir diferentes objetivos e agendas. Sobre este aspecto, cabe lembrar a afirmação de Marx e Engels (1998, p. 41) de que as "as idéias da classe dominante são, em cada época, as idéias dominantes, isto é, a classe que tem a força material na sociedade é, ao mesmo tempo, a sua força intelectual dominante". Extrapolando a afirmação, é possível afirmar que a memória de uma época também é a memória da classe dominante, daí a importância de disputá-la.

Da mesma forma, é importante observar que a memória pode ser construída e reconstruída a partir de fontes diversas, como, por exemplo, os documentos recolhidos aos arquivos brasileiros, os livros de uma determinada biblioteca pública, os registros audiovisuais de um colecionador particular ou, ainda, os relatos orais de pessoas que viveram determinadas situações. Isto é, a multiplicidade de fontes encerra desafios e possibilidades.

Tendo esse horizonte em vista, buscaremos discutir, neste artigo, a experiência do Centro de Referência das Lutas Políticas no Brasil (19641985) - Memórias Reveladas, iniciativa criada pelo governo federal, em 2009, com o objetivo de promover a difusão de informações contidas em conjuntos documentais do período da ditadura. Para tanto, buscaremos caracterizar o Memórias Reveladas, o que inclui analisar criticamente seus desafios, e situá-lo como parte de um quadro mais amplo de iniciativas recentes da justiça de transição no Brasil e na América do Sul.

O Brasil, assim como outros países sul-americanos, passou pela experiência de um regime ditatorial, com protagonismo das Forças Armadas, na segunda metade do século XX, como a Argentina (1976-1983), o Uruguai (1973-1985) e o Chile (1973-1990). Mas, ao contrário do Brasil, esses países aplicaram, logo após o restabelecimento de eleições diretas, mecanismos de justiça de transição com o objetivo de averiguar violações de direitos humanos praticadas no período ditatorial, incluindo mecanismos judiciais voltados à punição de torturadores e assassinos.

Em sentido contrário, os primeiros mecanismos brasileiros foram estabelecidos apenas na segunda metade da década de 1990, isto é, quase uma década após a transição política, e sem que ocorresse a responsabilização criminal ou mesmo cível de perpetradores de violações. O que pode ser explicado, pelo menos em parte, a partir das diferentes cir- 


\section{Revista pll paUtg}

\} MEMÓRIAS REVELADAS - STAMPA, I.; RODRIGUES, V. \}

cunstâncias históricas que condicionaram as transições do Brasil e de outros países da América do Sul.

$\mathrm{Na}$ Argentina, por exemplo, as eleições diretas foram restabelecidas em 1983, mesmo ano no qual se encerrou o governo militar e foi instalada a comissão da verdade daquele país, denominada de Comisión Nacional sobre la Desaparición de Personas (Conadep). Tal rapidez derivou, em grade parte, da desmoralização do regime militar argentino em virtude da derrota na Guerra das Malvinas (1982). Sem tempo para organizar a transição, a maior parte dos líderes da ditatura argentina terminou na cadeia, incluindo o último presidente da ditadura, Reynaldo Bignone, condenado, em 2011, aos 83 anos, à prisão perpétua por crime de lesa-humanidade.

Portanto, é possível afirmar que a experiência brasileira de justiça de transição é excepcionalmente tardia ${ }^{3}$, ainda que o seu ritmo tenha se acelerado nos últimos anos, com a criação, em 2009, do Centro de Referência Memórias Reveladas e, em 2011, com o estabelecimento da Comissão Nacional da Verdade (CNV) e com a promulgação da Lei de Acesso às Informações $(\mathrm{LAI})^{4}$.

\section{Justiça de transição: conceitos e desenvolvimento}

No Brasil, a expressão "justiça de transição" vem, em anos recentes $^{5}$, popularizando-se na imprensa e na academia, o que deriva, em grande parte, da criação da Comissão Nacional da Verdade e de dezenas de outras "comissões da verdade" estaduais, municipais, universitárias etc. De forma a esclarecer o que exatamente queremos dizer quando nos referimos à justiça de transição, cabe apontar, inicialmente, que entendemos esse conceito como aquele referente ao:

Amplo espectro de processos e mecanismos utilizados pela sociedade para que esta chegue a um determinado acordo sobre violações de direitos humanos ocorridas no passado, de forma a garantir a responsabilização dos culpados, promover a justiça e alcançar a reconciliação. Isso pode incluir tanto mecanismos judiciais como extrajudiciais, com diferentes níveis de participação da comunidade internacional [...] (ORGANIZAÇÃO DAS NAÇÕES UNIDAS, 2004, p. 4).

\footnotetext{
${ }^{3}$ A experiência internacional no campo da justiça de transição não registra nenhum outro caso no qual uma Comissão da Verdade foi estabelecida mais de duas décadas depois do fim do período de exceção ou conflito.

${ }^{4}$ A Comissão Nacional da Verdade foi estabelecida pela Lei 12.528, de 18 de novembro de 2011, mesma data de promulgação da Lei de Acesso às Informações (Lei 12.527/2011). A LAl é às vezes referida também pelo nome de Lei de Acesso a Informações ou, ainda, Lei de Acesso às Informações Públicas.

${ }^{5}$ Apenas a título de exemplo, cerca de $90 \%$ das matérias que trazem a expressão "justiça de transição" no portal de jornal de maior circulação nacional, Folha de São Paulo, datam de 2008 em diante, ano em que começou a ser discutido o PNDH-3 (Plano Nacional de Direitos Humanos no 3, aprovado em 2009) que, no âmbito do Estado, trouxe, pela primeira vez, a previsão de criação da Comissão Nacional da Verdade.
} 


\section{ReVistg all paUtg}

\} MEMÓRIAS REVELADAS - STAMPA, I.; RODRIGUES, V.\}

Com base nessa definição, consagrada pela Organização das Nações Unidas (ONU), Soares (2010) formulou um verbete no Dicionário de Direitos Humanos da Escola Superior do Ministério Público da União, disponível na Internet ${ }^{6}$, no qual define a justiça de transição como o:

[...] conjunto de abordagens, mecanismos (judiciais e não judiciais) e estratégias utilizados para enfrentar o legado de violência em massa do passado, atribuir responsabilidades, exigir a efetividade do direito à memória e à verdade, fortalecer as instituições com valores democráticos e para garantir a não repetição das atrocidades.

Por seu turno, Teitel (2011, p. 135), ao propor uma "genealogia" da justiça de transição, defende que ela pode ser definida como "a concepção de justiça associada a períodos de mudança política, caracterizados por respostas no âmbito jurídico que têm por objetivo enfrentar os crimes cometidos por regimes opressores do passado". Pouco difere esta definição da proposta por Van Zyl (2011, p. 47), segundo a qual a justiça de transição é "o esforço para a construção da paz sustentável após um período de conflito, violência em massa ou violação sistemática dos direitos humanos".

A partir dessas definições, pode-se extrair que a justiça de transição não é uma justiça especializada ${ }^{7}$, ou temática, com competência exclusiva para tratar de casos que envolvam violações maciças de direitos humanos. Antes, trata-se de um conjunto de "mecanismos, abordagens e estratégias" ou de "processos e mecanismos" utilizados em períodos de mudança política para enfrentar um legado histórico de violações de direitos humanos. Nessa direção, Mezarobba afirma que os "mecanismos, abordagens e estratégias" consistem em iniciativas tais como:

[...] processar criminosos; estabelecer comissões de verdade e outras formas de investigação a respeito do passado; esforços de reconciliação em sociedades fraturadas; desenvolvimento de programas de reparação para aqueles que foram mais afetados pela violência ou abusos; iniciativas de memória e lembrança em torno das vítimas; e a reforma de um amplo espectro de instituiçõ̃es públicas abusivas (como os serviços de segurança, policial ou militar). (2009, p. 37).

As comissões da verdade, bem como as iniciativas voltadas à abertura de arquivos de polícia política, têm vinculação direta com a efetivação do direito à memória e à verdade, no sentido de garantir, em primeiro lugar, que a verdade sobre as violações sistemáticas dos direitos humanos venha à tona. Em sequência, que os fatos relacionados a essas violações não

\footnotetext{
${ }^{6}$ Disponível em <http://www.esmpu.gov.br/dicionario/tiki-index.php>. Acesso em: 02 set. 2012.

${ }^{7}$ Nesse sentido, a justiça de transição não se assemelha, por exemplo, à Justiça Eleitoral ou à Justiça Militar, que são especializadas em determinados temas.
} 


\section{Revista pll paUtg}

\} MEMÓRIAS REVELADAS - STAMPA, I.; RODRIGUES, V. \}

sejam esquecidos para que não se repitam - o que pressupõe a adoção de uma série de iniciativas destinadas a garantir a preservação dessa memória.

É possível configurar o direito à memória e à verdade como aquele vinculado ao direto de conhecer um passado marcado por violações de direitos humanos. Trata-se, conforme aponta Silva Filho (2009, p. 78-79), de um direito transindividual que alcança "os mais diversos grupos da sociedade civil". Por outro lado, é um direito que representa "as mais diversas formas de reivindicação e concretização, não estando necessariamente preso à legislação estatal", tendo em vista que "sua formulação e reivindicação continuam a existir mesmo que a legislação imponha políticas de esquecimento".

Contudo, não há receita pronta para a adoção de mecanismos de justiça de transição, ou mesmo um pacote fechado de medidas necessárias, pois cada país tem seu próprio modo de lidar com o passado violento. Conforme aponta Hayner (2002, p. 7), a doutrina internacional é unânime ao afirmar que o processo de justiça de transição deve ser adaptado à realidade de cada país.

Trata-se, assim, de um processo necessariamente peculiar e nacional, no seio do qual cada governo, cada sociedade, deve encontrar seu próprio caminho para lidar com o legado de violência do passado, bem como para criar mecanismos que garantam a efetividade do direito à memória e à verdade, dentre outros. Nesse mesmo sentido, aponta a autora norteamericana que após décadas de aplicação da justiça de transição em diferentes países do mundo:

[...] resta agora muito claro que cada situação transicional vai diferir daquelas que vieram antes dela, e que e as necessidades, circunstâncias, cultura política e oportunidades potenciais vão também variar. Cada país que passa a abordar os desafios da justiça de transição o fará de forma única, de acordo com um conjunto de políticas e responsabilidades articuladas ao contexto nacional [...]. (HAYNER, 2002, p. 7)

Ou seja, não é possível falar de um único modelo "correto" para a justiça de transição, e não será jamais adequado impor modelos estrangeiros, por mais bem sucedidos que eles tenham sido alhures.

De toda forma, cabe referir Van Zyl (2011, p. 48), ao lembrar que, desde a década de 1990, o desenvolvimento da justiça de transição vem se dando, dentro da área dos direitos humanos, sob dois aspectos importantes. Em primeiro lugar, porque a justiça de transição deixou de ser uma "aspiração do imaginário", passando a representar "a expressão de obrigações legais vinculantes" a partir do seu progressivo reconhecimento por parte de tribunais nacionais, bem como de sua positivação na ordem internacional. Em segundo lugar, porque tem sido destacada a sua participação no processo democrático em muitos lugares do mundo, em especial na América Latina, na África e na Ásia. 


\section{Primeiros passos da justiça de transição no Brasil}

No Brasil, como antecedentes do processo que culminou com a criação do Memórias Reveladas, e que também deu origem à Lei de Acesso às Informações e à Comissão Nacional da Verdade, cite-se que a Lei da Anistia (Lei $n^{\circ}$ 6.683, de 28 de agosto de 1979) determinava, logo em seu

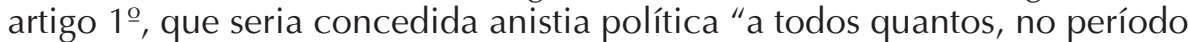
compreendido entre 02 de setembro de 1961 e 15 de agosto de 1979, tivessem cometido crimes políticos ou conexos com este", além de crimes eleitorais, e aos que tiveram os seus direitos políticos suspensos, aos servidores públicos e aos dirigentes e representantes sindicais que foram punidos com fundamento em atos institucionais e complementares.

Apesar de sua importância histórica, a Lei da Anistia não representou a consagração integral das teses defendidas pelo movimento popular pela anistia, que propugnava por uma anistia "ampla, geral e irrestrita". De fato, em seu artigo $2^{\circ}$, o referido diploma legal excluiu da anistia todos aqueles que tivessem tomado a via da ação armada contra o regime ditatorial, ao determinar que fossem excetuados os "condenados pela prática de crimes de terrorismo, assalto, sequestro e atentado pessoal". Por outro lado, conforme aponta Sales:

A aprovação da Lei 6.683, no dia 28 de agosto de 1979, que oficializou a anistia brasileira para os crimes praticados durante o período ditatorial, não significou o final das lutas de setores da sociedade civil pela redemocratização. Aprovada sob forte crítica do principal movimento organizado em prol da anistia, os Comitês Brasileiros pela Anistia (CBAs), essa lei nunca conseguiu aplacar as divergências em torno da forma como deveria ser o acerto de contas da sociedade com o seu passado ditatorial. Ao anistiar, ao mesmo tempo, torturadores e torturados, a lei abriu fissuras na sociedade que até hoje não foram fechadas. (2009, p. 27)

De toda forma, a Constituição Federal de 1988 trouxe inegável avanço para o desenvolvimento da justiça de transição no Brasil. Ainda hoje, o art. $8^{\circ}$ do Ato das Disposições Constitucionais Transitórias (ADCT) vem sendo utilizado como fundamento legal para a maior parte das ações de reparação tomadas pelo governo brasileiro. Diz o dispositivo:

É concedida anistia aos que, no período de 18 de setembro de 1946 até a data da promulgação da Constituição, foram atingidos, em decorrência de motivação exclusivamente política, por atos de exceção, institucionais ou complementares, aos que foram abrangidos pelo Decreto Legislativo oㅜ 18, de 15 de dezembro de 1961, e aos atingidos pelo Decreto-Lei oㅡ 864, de 12 de setembro de 1969, asseguradas as promoções, na inatividade, ao cargo, emprego, posto ou graduação a que teriam direito se estivessem em serviço ativo, obedecidos os prazos de permanência em atividade previstos nas leis e 
regulamentos vigentes, respeitadas as características e peculiaridades das carreiras dos servidores públicos civis e militares e observados os respectivos regimes jurídicos. (BRASIL, 1988)

Interessante observar que o referido dispositivo ampliou o leque de destinatários da anistia, principalmente ao deixar de fazer distinção entre aqueles que resistiram dentro da legalidade autoritária do período do regime civil-militar e aqueles que, ao contrário, tomaram o caminho das armas, como os militantes dos diversos grupos clandestinos de oposição ao regime ${ }^{8}$.

Da mesma forma, outro marco no processo de construção da justiça de transição "à brasileira" pode ser situado com a promulgação da Lei n 9.140, de 04 de dezembro de 1995, por intermédio da qual o Estado brasileiro reconheceu sua responsabilidade no desaparecimento forçado e assassinato de opositores políticos no período abrangido entre 02 de setembro de 1961 a 15 de agosto de $1979^{9}$.

Nesse sentido, o Estado brasileiro já reconhece, desde 1995, que as pessoas que desapareceram sob a custódia das forças de segurança do regime militar foram, na verdade, assassinadas. Esse reconhecimento possui uma significativa importância moral para os familiares de desaparecidos políticos, no sentido de afirmá-los como vítimas da repressão, e não, conforme apontava o discurso oficial do regime, como "gente que simplesmente resolveu mudar de lado e fugir" ${ }^{\prime 10}$. Por outro lado, tem também importância para a sobrevivência financeira das famílias dos desaparecidos políticos, ao viabilizar a obtenção de pensões e indenizações através de processos administrativos ou judiciais.

No que se refere à dimensão da reparação, cabe apontar que o art. $8^{\circ}$ do ADCT foi regulamentado pela Lei $\mathrm{n}^{\mathrm{O}} 10.559$, de 13 de novembro de 2002, por intermédio da qual se estabeleceu o "Regime do anistiado político" (art. 1ํㅜ caput), o qual implica no reconhecimento aos seguintes direitos: declaração da condição de anistiado político (art. 1ํㅗ I); reparação econômica de caráter indenizatório, em virtude de punição ou ameaça de punição sofrida durante o período do regime civil-militar brasileiro (II); contagem de tempo de serviço do profissional que foi compelido a se afastar de suas atividades (III); conclusão de curso para estudantes que foram obri-

\footnotetext{
${ }^{8}$ Como exemplos desses grupos, cite-se a Ação Libertadora Nacional (ALN), a Ação Popular (AP), o Comando de Libertação Nacional (Colina), a Vanguarda Armada Revolucionária Palmares (VAR-Palmares) e a Vanguarda Popular Revolucionária (VPR). Nenhum desses grupos sobreviveu aos anos 1970, desarticulados que foram pela forte repressão do Estado ditatorial.

${ }_{9}^{9}$ Posteriormente, o termo final foi alterado pela Lei ${ }^{\circ} 10.536$, de 14 de agosto de 2002, passando a vigorar o art. $1^{\circ}$ com a atual redação: "São reconhecidas como mortas, para todos os efeitos legais, as pessoas que tenham participado, ou tenham sido acusadas de participação, em atividades políticas, no período de 2 de setembro de 1961 a 5 de outubro de 1988, e que, por este motivo, tenham sido detidas por agentes públicos, achando-se, desde então, desaparecidas, sem que delas haja notícias". (BRASIL, 2002a).

${ }^{10}$ Esse discurso continua sendo reproduzido, de forma agressiva, por intermédio de sites e mailing lists de "clubes virtuais" de militares da reserva, tais como o "Terrorismo Nunca Mais" (www.ternuma.com.br), o "A Verdade Sufocada" (www.averdadesufocada.com) e o Clube Virtual dos Militares da Reserva e Reformados da Aeronáutica (www. reservaer.com.br). Daí a importância de detalhar as violações dos direitos humanos ocorridas no período de 19641985.
} 


\section{ReVistg all paUtg}

\} MEMÓRIAS REVELADAS - STAMPA, I.; RODRIGUES, V.\}

gados a abandonar os estudos (IV); e reintegração dos servidores públicos civis e dos empregados públicos punidos por motivos políticos (V). (BRASIL, 2002b). e Torelly:

Ainda sobre a dimensão da reparação, conforme apontam Abrão

É correta a percepção de que é a anistia brasileira - coerente com a luta histórica dos perseguidos políticos que a sustentaram - que levou a Comissão de Anistia a promover uma 'virada hermenêutica' nas leituras usualmente dadas a lei no 10.559/2002: não se trata da simples reparação econômica, mas gesto de reconhecimento das perseguições aos atingidos pelos atos de exceção. Tanto é assim que, a partir de 2007, a Comissão passou a formalmente 'pedir desculpas oficiais' pelos erros cometidos pelo Estado consubstanciado no ato declaratório da anistia política. (2010, p. 46)

Dessa forma, é possível conceituar que a primeira fase do desenvolvimento da justiça de transição, no Brasil, envolveu, principalmente, ações de reparação. Contudo, essa dimensão não se refere apenas ao aspecto financeiro, mas, também, à reparação moral ou simbólica, por meio do pedido de desculpas oficial do Estado brasileiro, além da recuperação de determinadas posições jurídicas, como a retomada de cursos acadêmicos por parte de alunos que foram perseguidos pelo regime militar, ou a reintegração de servidores públicos exonerados por motivos políticos.

\section{O Memórias Reveladas e o legado documental da ditadura militar}

No que se refere diretamente à abertura de arquivos da repressão política como meio de promoção do direito à memória e à verdade, o marco inicial desse processo deu-se por ocasião do V Fórum Social Mundial, realizado em Porto Alegre (RS), de 26 a 31 de janeiro de 2005, quando foi debatida a importância dos arquivos no Brasil e na América Latina, bem como sobre sua função estratégica na garantia de direitos humanos fundamentais.

Durante o evento, levantamentos preliminares, realizados pelo Arquivo Nacional, já apontavam que o Brasil era detentor do maior acervo documental sul-americano sobre a repressão política na segunda metade do século XX, dados que foram posteriormente confirmados, estimandose, atualmente, que o acervo é composto por aproximadamente 28 milhões de páginas de documentos textuais, além de documentos em outros formatos, como o acervo audiovisual e iconográfico ${ }^{11}$.

${ }^{11}$ O Relatório de 5 anos do Memórias Reveladas estima em 13 milhões da páginas o acervo sob custódia do Arquivo Nacional, além de outras 16 milhões de páginas sob guarda de arquivos públicos em todo o Brasil (MEMÓRIAS REVELADAS, 2014). 


\section{hevistg all pgutg}

\} MEMÓRIAS REVELADAS - STAMPA, I.; RODRIGUES, V. \}

No referido V Fórum Social Mundial, ficou consignada a promessa governamental de se criar um centro de referência capaz de reunir, de forma sistemática, dados e informações sobre o acervo arquivístico referente ao tema da repressão e resistência política e social no Brasil, entre as décadas de 1960 e 1980, sob a guarda de diversas entidades públicas e privadas de nosso país.

A proposta de constituição de um centro com tais características, formulada pela então Secretaria Especial dos Direitos Humanos, atualmente Secretaria de Direitos Humanos da Presidência da República, resultou na criação de um Grupo de Trabalho com o objetivo de "elaborar projeto para a implantação de um centro de referência que venha a abrigar informações [...] sobre as violações dos Direitos Humanos durante o período da ditadura militar no Brasil", conforme Portaria da SEDH no 21, de 21 de fevereiro de 2005.

O Centro de Referência Memórias Reveladas somente seria criado, contudo, em 13 de maio de 2009, tendo como objetivos institucionais "contribuir para o aprimoramento da democracia brasileira, possibilitando o acesso a documentos sobre o período do regime militar, inclusive suas imagens digitais", conforme o Relatório Anual do Centro de Referência Memórias Reveladas (2009, p. 3). Trata-se, portanto, de uma iniciativa que procura facilitar e popularizar o conhecimento da história recente do Brasil, a exemplo do Archivo Nacional de la Memoria da Argentina, que também tem por objetivo geral articular diversas instituições que têm sob sua guarda acervos do período ditatorial.

Antes mesmo da criação do Memórias Reveladas, cabe notar, já eram perceptíveis os primeiros movimentos em direção à abertura e difusão dos arquivos produzidos ou acumulados pela ditadura brasileira. Em decorrência do decreto $\mathrm{n}^{\circ}$ 5.584, de 18 de novembro de 2005, já tinham sido recolhidos ao Arquivo Nacional, em sua Coordenação Regional no Distrito Federal, os documentos arquivísticos públicos produzidos e recebidos pelos extintos Conselho de Segurança Nacional (CSN), Comissão Geral de Investigações - CGI e Serviço Nacional de Informações (SNI), o que ampliou em mais de vinte vezes o acervo da Coordenação Regional sobre o regime militar, passando de 2 para 43 fundos documentais ${ }^{12}$ (BRASIL, 2005).

O Brasil, país cujas dimensões se assemelham a de um continente, possui uma ampla gama de instituições e entidades custodiadoras de acervos, de diversas naturezas e cronologias. Esses depositórios da cultura nacional (COIMBRA, 2010) têm grande importância para que seja possível repensar a história contemporânea brasileira, incluindo a história do último período ditatorial. Conforme aponta Silva:

Nas sociedades contemporâneas, o direito à memória tem sido compreendido como parte dos direitos do homem. O direito à informação,

${ }^{12}$ Conjunto de documentos provenientes de uma mesma entidade produtora (ARQUIVO NACIONAL, 2005). 
com a revolução ocorrida nos arquivos a partir da Segunda Guerra Mundial, transcendeu as fronteiras nacionais - não se trata mais de uma questão restrita à cidadania. Diante da magnitude da questão, o Estado tem o dever de zelar pela preservação e pelo compartilhamento, através da divulgação, dos conjuntos documentais que se encontram sob a sua guarda. $\mathrm{E}$, ainda, procurar aquele patrimônio documental que, apesar de produzido por ele, encontra-se desconhecido da sociedade, perdido. (2008, p. 15).

Nesse sentido, a justiça de transição brasileira, em que pese o fato de ter se desenvolvido com excepcional atraso, conta com a vantagem estratégica na perspectiva dos direitos humanos, em relação a outras experiências sul-americanas, em especial as da Argentina, do Chile, e do Uruguai: tem à sua disposição farto material arquivístico.

Apenas a título de rápida comparação, o Chile, que experimentou um regime ditatorial particularmente brutal até mesmo para os padrões sul-americanos, tem poucos registros identificados de fontes oficiais sobre o período de exceção (1973-1990). Entretanto, cabe destacar a existência de acervos privados de Organizações Não Governamentais (ONGs) e arquivos da Igreja Católica, liberados para a consulta, com restrições para os documentos que possam vir a ferir a intimidade, a vida privada, a honra e a imagem das pessoas. $O$ pequeno acervo de origem pública, atualmente disponível no Archivo Nacional de Chile, foi acumulado, principalmente, a partir dos trabalhos da Comisión Nacional de Verdad y Reconciliación do Chile, e tem seu acesso regulado pelo Ministério do Interior, privilegiando os tribunais, os advogados e os familiares de vítimas da repressão (CHILE, 1991; SILVA, 2012).

No Uruguai, da mesma forma, são poucos os acervos públicos sobre o período da repressão (1973-1985), ainda que exista um número significativo de documentos, como no caso chileno, provenientes de ONGs, com acesso regulado pelas mesmas, levando-se em consideração o resguardo da intimidade, da vida privada, da honra e da imagem das pessoas.

Por seu turno, a Argentina criou, em 2003, durante o governo Néstor Kirchner (2003-2007), o Archivo Nacional de la Memoria, instituição ligada à Secretaria de Derechos Humanos, e encarregada de reunir, em microfilmes e meios digitais, documentos localizados em diversas instituições do país, públicas e privadas, tanto em nível municipal quanto provincial. Considerados em sua totalidade, esses diferentes acervos compreendem cerca de 2.000.000 (dois milhões) de páginas digitalizadas, além de publicações e registros de imprensa. Estão abertos à consulta, da mesma forma que os arquivos chilenos e uruguaios, isto é, com restrição de acesso a informações que possam ferir a intimidade, a vida privada, a honra e a imagem das pessoas (SILVA, 2012; ARGENTINA, 2011).

A criação do Centro de Referência Memórias Reveladas promoveu a articulação em rede de diversas entidades custodiadoras de acervos do 
período ditatorial, em todas as regiões do país. A rede é composta, majoritariamente, por arquivos públicos e centros de documentação de universidades, públicas e privadas. Como exemplo de atuação em rede, citese que, no âmbito dos acervos estaduais, o Memórias Reveladas desenvolveu ações em 13 estados $^{13}$, com o objetivo principal de garantir a preservação de acervos dos Departamentos de Ordem Política e Social (DOPS) ${ }^{14}$. As ações desse projeto, realizado entre os anos de 2009 e 2011, foram patrocinadas por intermédio da Lei Rouanet (Lei no 8.313, de 23 de dezembro de 1991), permitindo a criação de um banco de dados com informações sobre os acervos documentais da ditadura, disponível pela Internet.

Essas iniciativas levaram, em 2011, ao reconhecimento de acervos do Sistema Nacional de Informações e Contrainformação (Sisni) como patrimônio mundial da humanidade. O projeto "Rede de Informações e Contrainformação do Regime Militar no Brasil (1964-1985)", apresentado pelo Brasil, foi aprovado pelo Comitê Consultivo Internacional do Programa Memória do Mundo Memory of the World (MoW). A aprovação do projeto foi recomendada pelo Comitê Consultivo Internacional do Programa, que destacou a importância da documentação para a promoção dos direitos humanos e para a não repetição das atrocidades cometidas no período de 1964-1985. A Unesco criou este programa em 1992 com o objetivo de preservar e difundir amplamente documentos, arquivos e bibliotecas de grande valor mundial, buscando impedir, assim, que o patrimônio da humanidade seja esquecido. Desde que foi criado o programa, apenas um projeto brasileiro ("Coleção do Imperador - fotografias brasileiras e estrangeiras no século XIX") tinha sido aprovado anteriormente, em 2003.

A candidatura ao Memória de Mundo foi elaborada pelo Arquivo Nacional e por outras entidades parceiras do Centro de Referência Memórias Reveladas, incorporando fundos de órgãos centrais do Sisni custodiados pelo Arquivo Nacional, e de órgãos de informação dos estados da Federação (DOPS), estes custodiados por arquivos estaduais ${ }^{15}$.

Contudo, cabe apontar que uma limitação do Banco de Dados Memórias Reveladas refere-se ao baixo índice de digitalização de documentos de polícia política, evidenciando a necessidade de novos investimentos em ações que contemplem esse aspecto, que é fundamental para a ampla difusão das informações contidas nos acervos do período ditatorial. Até

\footnotetext{
${ }_{13}^{13}$ Alagoas, Ceará, Maranhão, Rio Grande do Norte, Sergipe, Pernambuco, Goiás, Espírito Santo, Minas Gerais, Rio de Janeiro, São Paulo, Paraná e Rio Grande do Sul.

${ }^{14}$ Os DOPS atuavam como braços estaduais do SISNI - Sistema Nacional de Informações e Contrainformação, que tinha como cabeça de sistema o SNI - Serviço Nacional de Informações.

${ }^{15}$ Foram contemplados os seguintes acervos: Serviço Nacional de Informações; Comissão Geral de Inquérito PolicialMilitar; Comissão Geral de Investigações; Conselho de Segurança Nacional; Delegacia de Ordem Política e Social do Ceará; Delegacia de Ordem Política e Social do Espírito Santo; Delegacia de Ordem Política e Social do Maranhão; Delegacia de Ordem Política e Social do Paraná; Delegacia de Ordem Política e Social de Pernambuco; Departamento Autônomo de Ordem Política e Social do Estado do Rio de Janeiro; Departamento de Ordem Política e Social de Goiás; Departamento de Ordem Política e Social de Minas Gerais; Departamento de Ordem Política e Social do Estado da Guanabara; Departamento Estadual de Ordem Política e Social de São Paulo.
} 


\section{ApVistg ell paUtg}

\} MEMÓRIAS REVELADAS - STAMPA, I.; RODRIGUES, V.\}

fevereiro de 2014, pouco mais de 30.000 representantes digitais constavam no Banco de Dados, número modesto levando-se em consideração o gigantesco acervo documental brasileiro. Em sentido contrário, o Banco de Dados traz informações sobre mais de 300.000 registros documentais do período de 1964-1985, ainda que boa parte dos documentos em questão não tenha sido digitalizada. O Banco de Dados pode ser acessado no endereço <www. memoriasreveladas.gov.br>. Da mesma forma, cabe destacar que foram disponibilizados para consulta presencial mais de 10 milhões de documentos digitalizados do período.

Além desse, outro desafio do Memórias Reveladas foi o estabelecimento de critérios legais para a abertura dos arquivos da ditadura. Anteriormente à aprovação da Lei 12.527/2011(LAI), o acesso a informações públicas de proveniência federal, no Brasil, encontrava-se regulado por dispositivos constantes na Lei no 8.159, de 8 de janeiro de 1991 (derrogada), que dispõe sobre a política nacional de arquivos públicos e privados para o país, e na Lei no 11.111, de 5 de maio de 2005 (ab-rogada), que regulamentava a parte final do disposto no inciso XXXIII do art. $5^{\circ}$ da Constituição, em especial no que tange à classificação de documentos públicos no grau de ultrassecretos.

Da mesma forma, a legislação anterior trazia a previsão de prorrogação ad aeternum do prazo de sigilo no grau ultrassecreto, embora essa faculdade tenha sido utilizada residualmente, de tal forma que, segundo Silva (2012), a questão do sigilo em razão da segurança da sociedade e do Estado praticamente não se afigurou, após 2005, como um elemento impeditivo para o acesso público à documentação do regime militar, até mesmo pelo decurso de prazo.

Contudo, quanto ao estabelecimento de critérios que pudessem nortear o acesso aos documentos do período do regime militar que trouxessem informações pessoais, a regulamentação em questão não era de grande utilidade, uma vez que ambas as leis 8.159/1991 e 11.111/2005 limitaramse a reproduzir ${ }^{16}$ o texto constitucional, ao determinarem que tanto o direito de acesso a informações, quanto o direito à intimidade, à vida privada, à honra e à imagem, deveriam ser observados, sem estabelecer qualquer indicativo de como isso deveria, na prática, ser feito (BRASIL, 1991; 2005). O legislador, aliás, lembrou-se de estabelecer, na Lei 8.159/1991, em até 100 (cem) anos o prazo de sigilo para os documentos que versassem sobre a intimidade, esquecendo-se, contudo, de estabelecer quais seriam os critérios para a fixação desse prazo, bem como de que forma se faria a gradação sugerida pela preposição "até".

\footnotetext{
${ }^{16} \mathrm{O}$ artigo 22 da Lei 8.159/1991 estabelecia que "É assegurado o direito de acesso pleno aos documentos públicos" ao passo que o $\S 1^{\circ}$ do art. 23 estabelecia que os documentos cuja divulgação pusesse em risco a segurança da sociedade e do Estado, bem como aqueles necessários ao resguardo da inviolabilidade da intimidade, da vida privada, da honra e da imagem das pessoas são originariamente sigilosos. (BRASIL, 1991). A mesma dualidade pode ser encontrada nos artigos $2^{\circ}$ e $7^{\circ}$ da Lei $11.111 / 2005$. (BRASIL, 2005)
} 
Some-se a essa dificuldade o fato de que os conceitos de "intimidade", "vida privada", "honra" e "imagem", apesar de razoavelmente bem delimitados pela doutrina jurídica, não estão descritos em lei ou regulamento, e que a Lei 8.159/1991, ao mesmo tempo em que determinava à administração pública que franqueasse a consulta aos documentos públicos (art. 5), também ameaçava com a responsabilização "penal, civil e administrativa" de quem violasse o sigilo da informação (art. $6^{\circ}$ ), e não é preciso muito mais ${ }^{17}$ para caracterizar o quadro de confusão e insegurança que antecedeu a aprovação da Lei 12.527/2011 (Lei de Acesso às Informações LAI). (BRASIL, 1991; 2011).

Esse quadro de insegurança jurídica, como é natural, não contribuiu para o estabelecimento, no Brasil, de critérios universais e homogêneos de acesso nos órgãos detentores de acervos de polícia política. No que se refere especialmente aos órgãos federais, foi somente com a nova LAI que se estabeleceu o acesso integral ${ }^{18}$ a documentos referentes aos órgãos de repressão política no período de 1964-1985. Antes, esse acesso era restrito aos próprios retratados na documentação, ou, ainda, aos seus familiares, no caso de desaparecidos políticos ou pessoas já falecidas - e somente porque, nessas hipóteses, não era possível configurar qualquer risco de violação ao direito à intimidade, à vida privada, à honra e à imagem de pessoas.

Atualmente, a partir de sugestões do Memórias Reveladas e do Arquivo Nacional, a LAl determina que qualquer pessoa pode ter acesso aos documentos recolhidos aos arquivos públicos, sem que precise sequer declinar as razões pelas quais deseja ter acesso a determinado documento ${ }^{19}$. No Arquivo Nacional, já é possível acessar, presencialmente, cerca de 12 milhões de documentos digitalizados, e nos quais é possível realizar a busca por palavras e expressões de forma automatizada ${ }^{20}$. A digitalização foi planejada em conjunto com a Comissão Nacional da Verdade. No quadro a seguir, estão destacados alguns desses fundos documentais, de acordo com o volume:

\footnotetext{
${ }_{17}$ De toda forma, é possível citar, ainda, que o Decreto 5.584, de 18 de novembro de 2005, determinava, em seu art. 10, restrição de acesso aos documentos que se referissem "à intimidade da vida privada de pessoas". (BRASIL, 2005) ${ }^{18}$ Alternativamente, $\mathrm{o}$ art. $7^{\circ}$ da Lei 11.111/2005 permitia o acesso parcial às informações "por meio de certidão ou cópia do documento, que expurgue ou oculte a parte sobre a qual recai o disposto no inciso X do caput do art. 5으 Constituição Federal". (BRASIL, 2005)

${ }^{19}$ A Lei de Acesso às Informações aplica-se a órgãos e entidades dos três poderes, em todos os níveis da Federação. Em alguns estados, como no Rio de Janeiro, São Paulo e Espírito Santo, a LAl foi regulamentada por decretos estaduais. ${ }^{20}$ No jargão arquivístico, foi realizada a "ocerização" Optical Character Recognition (OCR), isto é, o reconhecimento óptico de caracteres.
} 
Quadro 1: acervos do período de 1964-1985

\begin{tabular}{|l|c|}
\hline \multicolumn{2}{|c|}{ Os mais volumosos acervos do período de 1964-1985 (Arquivo Nacional) } \\
\hline \multicolumn{1}{|c|}{ Nome do fundo } & No de páginas \\
\hline Serviço Nacional de Informações & 3.499 .974 \\
\hline Estado Maior das Forças Armadas & 837.493 \\
\hline Divisão de Segurança e Informações do MRE & 634.565 \\
\hline Conselho de Segurança Nacional & 561.758 \\
\hline Divisão de Segurança e Informações do Ministério da Justiça & 300.300 \\
\hline Divisão de Informações da Petrobras & 282.178 \\
\hline Instituto de Pesquisas e Estudos Sociais & 196.000 \\
\hline
\end{tabular}

Fonte: Relatório de digitalização de acervos de interesse da CNV, de 27 de maio de 2014. Rio de Janeiro: Arquivo Nacional, 2014.

Cabe apontar, também, que, apesar dos grandes avanços obtidos com a LAI, permanecem desafios para o acesso à informação produzida ou acumulada pelo Estado brasileiro no período de 1964-1985. De forma geral, podemos resumir esses desafios em relação à questão "desaparecimento" de acervos do Sistema Nacional de Informações e Contrainformação (Sisni), bem como ao fato de que diversos acervos de interesse para a reconstrução da memória histórica, tanto públicos quanto privados, ainda não passaram por tratamento arquivístico adequado, que permita não somente a conservação, mas também a difusão das informações contidas nesses documentos.

Conforme indicado por Ishaq e Franco (2008), dos 249 órgãos identificados como componentes desse sistema, apenas 15\% tiveram seus acervos recolhidos ao Arquivo Nacional. Ainda que inúmeros novos recolhimentos tenham sido registrados após 2008, sobretudo entre os anos de 2011 a 2013, o que elevou o percentual para aproximadamente $20 \%$, a maior parte dos conjuntos documentais do Sisni permanece não localizada, incluindo os acervos do Centro de Informação do Exército (CIE), Centro de Informação da Marinha (Cenimar) e a maior parte do acervo ${ }^{21}$ do Centro de Informações de Segurança da Aeronáutica (Cisa) que, em tese, poderiam conter informações importantes sobre desaparecimentos forçados e outras violações de direitos humanos.

Em grande parte, os novos recolhimentos são uma resposta à iniciativa do Memórias Reveladas, levada a efeito por intermédio do Arquivo

\footnotetext{
${ }^{21}$ Em 2010, foram localizadas, em meio a um lote de documentos de natureza administrativa da Aeronáutica, 189 caixas de documentos do Cisa, contendo, aproximadamente, 50 mil documentos referentes ao período de 1964 a 1985, incluindo informações sobre Ernesto Che Guevara, Fidel Castro e Carlos Lamarca. Os documentos foram recolhidos ao Arquivo Nacional e estão acessíveis. Não obstante, trata-se de apenas uma parcela da documentação total do Cisa, e não é possível perceber que foi feita uma seleção (SILVA, 2012).
} 


\section{hevistg all pgutg}

\} MEMÓRIAS REVELADAS - STAMPA, I.; RODRIGUES, V.\}

Nacional, que solicitou a todos os órgãos do governo federal que realizassem buscas por documentos do período de 1964-1985, em especial da documentação de órgãos do extinto Sisni. Entre os acervos recolhidos, destacase o da divisão de informações da Petrobras, tanto pelo grande volume (131.277 microfichas, 426 rolos de microfilmes, e 1,32m de documentos textuais), quanto por representarem um testemunho da repressão praticada contra a categoria dos trabalhadores petroleiros.

Se levarmos ainda em consideração os conjuntos documentais que, apesar de localizados, ainda não foram objeto de tratamento arquivístico que permitisse a ampla difusão de informações, chegaremos à conclusão de que há um rico patrimônio documental sobre o período da ditadura militar a ser prospectado no Brasil.

Nesse sentido, o estabelecimento da Comissão Nacional da Verdade representou, e talvez ainda represente, uma oportunidade ímpar para a localização de importantes registros da repressão política no Brasil. Será de fato de se lamentar se nenhuma pista sobre o destino da documentação dos centros de inteligências das Forças Armadas for descoberta até o fim das atividades da Comissão, bem como para que seja favorecida a alocação de recursos necessários ao tratamento arquivístico de acervos que foram localizados, mas que permanecem em geral inacessíveis por falta de tratamento técnico. Ou seja, não obstante a importância de tais iniciativas, é necessário torná-las políticas de Estado para garantir a continuidade e o aprimoramento dessas ações.

Os relatórios parciais divulgados pela Comissão Nacional da Verdade como, por exemplo, o relatório do caso Rubens Paiva, tornaram evidente a importância de iniciativas como o Memórias Reveladas, uma vez que os arquivos são fundamentais para que se possa promover a recuperação da história de um povo, sobretudo quando essa história se refere a um passado no qual ocorreram graves violações de direitos humanos perpetradas por motivos políticos. No caso em questão, somente foi possível desmontar a versão dos fatos dada pelo general José Antônio Nogueira Belham, implicado na morte e desaparecimento do corpo do ex-deputado Rubens Paiva, a partir da utilização de documentos de arquivo, produzidos pelo próprio Estado repressor e, atualmente, recolhidos ao Arquivo Nacional.

Ainda sobre esse aspecto, cabe apontar que a importância dos acervos da repressão, sobretudo aqueles relacionados à polícia política, não reside no fato de conterem "verdades". Conforme alertou Marx (1981, p. 939), no volume VI de O Capital, "toda ciência seria supérflua se houvesse coincidência imediata entre a aparência e a essência das coisas". Nesse sentido, os acervos esclarecem menos a respeito da verdade sobre os "fatos" que os agentes da ditadura pretendiam registrar, e mais sobre a forma como se produzia e se controlava a informação durante o regime autoritário.

Igual realidade se percebe nos trabalhos desenvolvidos no âmbito da Comissão de Anistia, órgão do Ministério da Justiça que promove políticas 


\section{hevistg all paUtg}

\} MEMÓRIAS REVELADAS - STAMPA, I.; RODRIGUES, V.\}

de reparação, e cujos processos são, normalmente, instruídos por depoimentos de vítimas e de testemunhas de graves violações de direitos humanos e, também, por documentos públicos, que funcionam como elemento de corroboração indireta dos relatos (documentos de polícia política, em regra, não confirmam diretamente a versão da vítima. Mas a partir das omissões e deturpações desses registros, ou do mero descuido do agente da repressão, que registrou "o que não deveria", ou aquilo que não parecia tão importante à época, é que frequentemente se pode chegar à verdade).

Outras vertentes de atuação do Centro de Referência Memórias Reveladas referem-se à promoção de eventos. Cite-se, como exemplos, o Seminário Acesso a Informações e Direitos Humanos (2010), a Oficina sobre Fontes para o Estudo do Regime Militar (2010), o 1o Seminário Internacional Documentar a Ditadura (2013), o $3^{\circ}$ Seminário Internacional O Mundo dos Trabalhadores e seus Arquivos - Direito à Memória e à Verdade (2013) e o recente Seminário Ditadura e Transição Democrática: 5 anos do Memórias Reveladas nos 50 anos do Golpe de 1964 (2014). Todos esses eventos, de âmbito nacional ou internacional, promovidos pelo Memórias Reveladas, alguns em parceria com universidades e/ou com instituições parceiras do Centro, que foram oferecidos em várias regiões brasileiras, com o objetivo de qualificar técnicos e difundir as boas práticas nos campos da arquivologia e da ciência da informação. Esses encontros também se configuraram como fóruns privilegiados para debates acadêmicos sobre questões polêmicas, como o acesso à documentação da ditadura (antes da promulgação da Lei de Acesso às Informações), as estratégias adequadas de preservação docu-mental, a localização de documentação desaparecida, o baixo investimento de diferentes esferas governamentais no setor de arquivos, dentre outras questões.

A interlocução do Memórias Reveladas com o público acadêmico é feita, também, por intermédio da Comissão de Altos Estudos do Memórias Reveladas, órgão assessor do Centro de Referência, e composto por especialistas de diferentes áreas e vindos de todas as regiões do país, e até mesmo de fora dele, dedicados à temática da ditadura. Foi a partir dos insumos da Comissão de Altos Estudos que, em 2009, foi criado o Prêmio de Pesquisa Memórias Reveladas, que premia autores de trabalhos monográficos que utilizem fontes documentais pertinentes ao período da ditadura. De periodicidade bienal, o prêmio vem atraindo a participação de dezenas de pesquisadores a cada edição ${ }^{22}$.

O concurso monográfico já se encontra em sua terceira edição, e é aberto para participação de qualquer pessoa, independente de titulação acadêmica.

\footnotetext{
${ }^{22}$ A edição 2010 do concurso premiou os trabalhos "O Terror Renegado" (Alessandra Gasparotto), "Todo o Leme a Bombordo" (Anderson da Silva Almeida) e "No Centro da Engrenagem" (Mariana Joffily), todos já publicados. Os livros vencedores da edição 2012 estão no prelo: 'Dossiê Itamaracá' (Joana Santos Rolemberg Côrtes), "Os Vigilantes da Ordem" (Pâmela de Almeida Resende) e "Os protagonistas do Araguaia" (Patrícia Sposito Mechi).
} 


\section{Revista pll paUtg}

\} MEMÓRIAS REVELADAS - STAMPA, I.; RODRIGUES, V. \}

Não obstante todas essas iniciativas e a importância das mesmas para a construção de uma política nacional de arquivos, e consequentemente de preservação e difusão da memória nacional, cabe apontar que o Centro de Referência não conta com orçamento próprio, o que levanta questões a respeito da continuidade de suas atividades no futuro. Isto é, de seu reconhecimento enquanto ação de Estado, bem como representa obstáculo para o aperfeiçoamento e atualização de seus recursos tecnológicos, como bancos de dados digitais.

Da mesma forma, a gestão de uma rede de noventa instituições parceiras, no Brasil e no exterior - ainda que o Centro seja administrado e tenha grande parte de suas ações financiadas pelo Arquivo Nacional - requer uma estrutura robusta, ainda mais se forem levadas em consideração as assimetrias regionais típicas da realidade socioeconômica brasileira, e seus impactos para a gestão de uma rede de cooperação.

Fazemos referência à disparidade de recursos técnicos, financeiros e humanos entre instituições como o Arquivo Nacional em relação a arquivos públicos dotados de poucos recursos e com infraestrutura tecnológica defasada ou praticamente inexistente. A título de exemplo, antes da criação do Memórias Reveladas, o Arquivo Público do Estado do Ceará não possuía conexão com a Internet, ao passo que o Arquivo Histórico do Rio Grande do Sul não possuía quadro próprio de servidores. Atualmente, em que pese a permanência de várias carências, ambos os arquivos estaduais encontramse melhor capacitados tecnicamente, e destacam-se, no âmbito da Rede Memórias Reveladas, pelo bom nível de organização de seus acervos sobre o período da ditadura.

Dessa forma, a criação, entre os anos de 2009 e 2011, de mecanismos especificamente dedicados aos arquivos da ditadura, visando à promoção do direito à memória e à verdade, contribui para combater o que Silva Filho (2009, p. 78-79) denominou de "políticas de esquecimento", conceito que abrange não somente ações que visam apagar ou reescrever a história da ditadura militar, como também a falta de políticas de memória para o período (dimensão negativa).

Os conjuntos documentais da ditadura são fundamentais para determinar, no presente, as responsabilidades por injustiças e crimes, principalmente quando cometidos em períodos de exceção por agentes do Estado ou a seu mando. Sob outro aspecto, mais geral, permitem identificar as estruturas e contextos que permitiram o estabelecimento da ditadura e, principalmente, sua manutenção por mais de duas décadas, o que deixou marcas inegáveis no aparelho estatal e na própria sociedade brasileira.

Assim, a adoção de políticas de memória específicas para enfrentar o legado histórico de violações sistemáticas dos direitos humanos, como as que ocorreram entre 1964 a 1985, deve ter por objetivo não somente garantir a compreensão do que ocorreu, mas também reforçar o entendimento 


\section{ReVistg all paUtg}

\} MEMÓRIAS REVELADAS - STAMPA, I.; RODRIGUES, V.\}

coletivo de que são necessárias estratégias para enfrentar, no presente, os desafios que se impõem à nossa democracia.

Nessa direção, a criação do Memórias Reveladas suscitou, pela primeira vez, a cooperação entre a União, Estados e o Distrito Federal para a integração em rede de arquivos e instituições públicas e privadas em comunicação permanente. Nessa mesma perspectiva, ao articular esforços em rede, o Memórias Reveladas diminuiu custos e permitiu a difusão de boas práticas para uma ampla gama de instituições, servindo como exemplo para a adoção de iniciativas no campo dos direitos humanos, em especial no que se refere à efetivação de políticas de cooperação de informações arquivísticas e à promoção do direito à memória e à verdade no país.

Invertendo a lógica do Sisni, rede de vigilância política da ditadura militar, o Memórias Reveladas reconstrói, a partir de documentos do próprio Sisni ou a ele relacionados, uma rede de informações outrora sigilosas, agora postas à disposição da cidadania, para a defesa de direitos e para o conhecimento da história recente do país.

A questão ganha importância, sobretudo, quando tomamos em conta a infeliz permanência, no Brasil, de violações sistemáticas dos direitos humanos praticadas por agentes do Estado, como são exemplos a utilização generalizada da tortura no sistema carcerário e a ocorrência de execuções extrajudiciais.

E o que foi feito é preciso conhecer para melhor prosseguir ${ }^{23}$ na construção da democracia brasileira. São milhões de páginas digitalizadas e preservadas no Arquivo Nacional e em outros arquivos públicos. Outros milhões de documentos, em instituições públicas e privadas, aguardam projetos de digitalização e difusão de informações em rede. Além do patrimônio documental que, embora produzido pelo Estado, permanece ainda hoje desaparecido. É patrimônio do povo brasileiro, e bandeira de luta de nosso próprio tempo.

\section{Considerações finais}

Neste artigo, buscou-se abordar a criação e desenvolvimento do Centro de Referência das Lutas Políticas no Brasil (1964-1985) - Memórias Reveladas, identificado como um mecanismo de justiça de transição voltado para a questão dos arquivos do período da ditadura militar.

Para tanto, foi necessário, ainda que rapidamente, discutir o próprio conceito de justiça de transição e, principalmente, refletir como ela vem se desenvolvendo no Brasil, bem como identificar as peculiaridades que a conformam.

${ }^{23}$ Trecho da música "O Que Foi Feito Deverá" (Milton Nascimento, Fernando Brant) / "O Que Foi Feito de Vera" (Milton Nascimento, Márcio Borges), cujos versos terminam dizendo: "De vera nunca se acabe/ Abelha fazendo o seu mel/ No canto que criei/ Nem vá dormir como pedra/ E esquecer o que foi feito de nós". In: Clube Da Esquina 2, 1978. 


\section{Revistg all PaUt?}

\} MEMÓRIAS REVELADAS - STAMPA, I.; RODRIGUES, V. \}

A justiça de transição foi compreendida como um conjunto de mecanismos, abordagens e estratégias, utilizados em períodos de mudança política, para enfrentar legados históricos de violações de direitos humanos. Ou seja, falar em justiça de transição é falar em um determinado rol de ações que devem ser executadas em períodos de pós-conflito, visando a não repetição de atrocidades.

Por outro lado, procurou-se compreender as características próprias que a justiça de transição no Brasil pós-1985 assumiu, isto é, após o fim da ditadura militar brasileira, articulando o Memórias Reveladas a dois outros mecanismos de justiça de transição recentemente criados, a Comissão Nacional da Verdade e a nova Lei de Acesso às Informações, que têm vinculação direta com o chamado direito à memória e à verdade, compreendido como um direito transindividual de saber a verdade sobre violações de direitos humanas ocorridas no passado.

No que se refere ao acesso a informações públicas, coube apontar que o Brasil é detentor do maior conjunto documental de origem pública sobre a repressão política na região sul-americana. Daí a importância do Memórias Reveladas, que busca articular diferentes instituições custodiadoras de acervos, e da nova Lei de Acesso às Informações, que veio disciplinar adequadamente o acesso a essa gigantesca documentação do período do regime militar.

O Memórias Reveladas surge a partir de pressões da sociedade brasileira, reforçando-se a compreensão de que a memória é um bem público que se encontra na base do processo de construção da identidade social, política e cultural de um país. Nesse sentido, o Centro é o resultado visível de várias iniciativas em prol da consolidação de uma política pública de valorização e preservação do patrimônio documental brasileiro.

O contínuo crescimento da rede de instituições parceiras ("Rede Memórias Reveladas"), que em 2014 atingiu noventa integrantes, indica, por um lado, que o Memórias Reveladas é atualmente reconhecido como um importante pólo difusor de informações sobre o período da ditadura militar e, por outro lado, evidenciou a necessidade de ampliar e aperfeiçoar as ações do Centro de Referência.

Assim, ao mesmo tempo em que se deve reconhecer os avanços dos últimos anos, faz-se necessário, também, reconhecer o muito que há a ser feito, suplantando o silêncio e o esquecimento por intermédio de ações concretas e permanentes de promoção do direito à memória e à verdade. 


\section{hevistg all paUtg}

\} MEMÓRIAS REVELADAS - STAMPA, I.; RODRIGUES, V. \}

\section{Referências}

ABRÃO, P.; TORELLY, M. D. Justiça de transição no Brasil: a dimensão da reparação. In: SANTOS, B. de S. et al (Org.). Repressão e memória política no contexto Ibero-Brasileiro: estudos sobre Brasil, Guatemala, Moçambique, Peru e Portugal. Brasília: Ministério da Justiça/Comissão de Anistia; Portugal: Universidade de Coimbra/Centro de Estudos Sociais, 2010.

ARGENTINA. Relatório anual do Archivo Nacional de la Memoria. Disponível em: <www.derhuman.jus.gov.ar/anm/index.html>. Acesso: 11 out. 2012. Buenos Aires: Secretaria de Los Derechos Humanos, 2011.

ARQUIVO NACIONAL. Dicionário brasileiro de terminologia arquivística. Rio de Janeiro: Arquivo Nacional, 2005.

- Relatório de digitalização de acervos de interesse da CNV, de 27 de maio de 2014. Rio de Janeiro: Arquivo Nacional, 2014.

BRASIL. Lei no . 6.683, de 28 de agosto de 1979. Concede anistia e dá outras providências. Disponível em: <http://www.planalto.gov.br/ccivil_03/ leis/L6683.htm>. Acesso em: 18 nov. 2012.

. Constituição da República Federativa do Brasil (1988). Disponível em <http://www.planalto.gov.br/ccivil_03/constituicao/constituicao.htm>. Acesso 13 set. 2012.

. Lei $n^{\circ} 8.159$, de 8 de janeiro de 1991. Dispõe sobre a política nacional de arquivos públicos e privados e dá outras providências. Disponível em: <http://www.planalto.gov.br/ccivil_03/leis/L8159.htm>. Acesso em: 14 nov. 2012.

. Lei no 9.140, de 4 de dezembro de 1995. Reconhece como mortas pessoas desaparecidas em razão de participação, ou acusação de participação, em atividades políticas, no período de 2 set. 1961 a 15 de agosto de 1979, e dá outras providências (2002a). Disponível em: <http://www. planalto.gov.br/ccivil_03/leis/L9140.htm>. Acesso em: 18 nov. 2012.

. Lei $n^{-} 10.536$, de 14 de agosto de 2002. Altera dispositivos da Lei $n^{0}$ 9.140, de 4 de dezembro de 1995, que reconhece como mortas pessoas desaparecidas em razão de participação, ou de acusação de participação, em atividades políticas, no período de 2 set. 1961 a 15 de agosto de 1979, e dá outras providências (2002b). Disponível em: <http://www. planalto. gov.br/ccivil_03/leis/2002/l10536.htm>. Acesso em: 12 jun. 2014.

. Lei no 10.559, de 13 de novembro de 2002. Regulamenta o art. $8^{\circ}$ do Ato das Disposições Constitucionais Transitórias e dá outras providências. Disponível em: <http://www.planalto.gov.br/ccivil_03/leis/2002/ |10559.htm>. Acesso em: 12 jun. 2014. 


\section{hevistg all pgutg}

\} MEMÓRIAS REVELADAS - STAMPA, I.; RODRIGUES, V.\}

BRASIL. Lei no 11.111, de 5 de maio de 2005. Regulamenta a parte final do disposto no inciso XXXIII do caput do art. 5o da Constituição Federal e dá outras providências. Disponível em: <http:// www.planalto.gov.br/ccivil_03/_ato2004-2006/2005/lei/l11111.htm>. Acesso em: 14 nov. 2012.

. Decreto $n^{\circ}$ 5.584, de 18 de novembro de 2005. Dispõe sobre o recolhimento ao Arquivo Nacional dos documentos arquivísticos públicos produzidos e recebidos pelos extintos Conselho de Segurança Nacional CSN, Comissão Geral de Investigações - CGI e Serviço Nacional de Informações - SNI, que estejam sob a custódia da Agência Brasileira de Inteligência - ABIN. Disponível em: <http://www.planalto.gov.br/ccivil_03/ Ato2004-2006/2005/Decreto/D5584.htm>. Acesso em: 14 nov. 2012.

. Programa Nacional de Direitos Humanos (PNDH 3). Brasília: Secretaria Especial dos Direitos Humanos da Presidência da República, 2009.

. Lei $n^{\circ} 12.527$, de 18 de novembro de 2011. Regula o acesso a informações previsto no inciso XXXIII do art. $5^{\circ}$, no inciso II do $\S 3^{\circ}$ do art. 37 e no $\S 2^{\circ}$ do art. 216 da Constituição Federal; altera a Lei no 8.112, de 11 de dezembro de 1990; revoga a Lei no 11.111, de 5 de maio de 2005, e dispositivos da Lei $n^{\circ} 8.159$, de 8 de janeiro de 1991; e dá outras providências. Disponível em: <http://www.planalto.gov.br/ccivil_03/_ato20112014/2011/lei/l12527.htm>. Acesso em: 18 nov. 2012.

. Decreto 7.724, de 18 de novembro de 2011. Regulamenta a Lei $\mathrm{n}^{\circ}$ 12.527, de 18 de novembro de 2011, que dispõe sobre o acesso a informações previsto no inciso XXXIII do caput do art. $5^{\circ}$, no inciso II do $\S 3^{\circ}$ do art. 37 e no $\S 2^{\circ}$ do art. 216 da Constituição. Disponível em: <http:// www.planalto.gov.br/ccivil_03/_ato2011-2014/2012/Decreto/D7724.htm >. Acesso em: 8 nov. 2012.

. Lei no 12.528, de 18 de novembro de 2011. Cria a Comissão Nacional da Verdade no âmbito da Casa Civil da Presidência da República. Disponível em: <https://www.planalto.gov.br/ccivil_03/_ato2011-2014/ 2011/lei/l12528.htm>. Acesso em: 18 nov. 2012.

. Relatório parcial de pesquisa. Brasília: Comissão Nacional da Verdade, 2013. Disponível em: <http://www.cnv.gov.br/images/pdf/cnv_ parcial.pdf>. Acesso em: $1^{\circ}$ set. 2013.

CARBONARI, P. C. PNDH 3: Por que mudar? Portal Carta Maior. Disponível em: <www.cartamaior.com.br/templates/materiaMostrar.cfm?materia_id= 16334>. Acesso em: 17 set. 2012.

CHILE. Comisión Nacional de Verdad y Reconciliación. Santiago, 1991. Disponível em: <www.derechoschile.com/basicos/ddhhchile/rettig/english/ rettigengindex1.html>. Acesso em: 11 out. 2012. 


\section{hevistg all paUtg}

\} MEMÓRIAS REVELADAS - STAMPA, I.; RODRIGUES, V.\}

COIMBRA, M. N. O dever de não esquecer como dever de preservar o legado histórico. In: SANTOS, B. S. et al (Org.). Repressão e memória política no contexto ibero-brasileiro - estudos sobre Brasil, Guatemala, Moçambique, Peru e Portugal. Brasília: Ministério da Justiça/Comissão de Anistia; Portugal: Universidade de Coimbra/Centro de Estudos Sociais, 2010.

COMPARATO, F. K. Afirmação histórica dos direitos humanos. São Paulo: Editora Saraiva, 2010.

CONADEP. Report of Conadep (National Commission on the Disappearance of Persons)-1984. Disponível em: <http://www.desaparecidos.org/nunca mas/web/english/library/nevagain/nevagain_001.htm>. Acesso em: 19 de set. 2012.

DATAFOlHA. Pesquisa, 31 de março de 2014. Disponível em: <http://da tafolha.folha.uol.com.br/opiniaopublica/2014/03/1433561-brasileirospreferem-democracia-mas-sao-criticos-com-seu-funcionamento.shtml>. Acesso em: 12 jun. 2014.

HAYNER, P. B. Unspeakable truths: facing the challenge of Truth Commissions. Nova York: Routledge, 2002.

ISHAQ, V.; FRANCO, P. E. Reveladas. Os acervos dos órgãos federais de segurança e informações do regime militar no Arquivo Nacional. Acervo: Revista do Arquivo Nacional, dossiê Arquivos do regime militar, vol. 21, no 02 , jul/dez 2008.

MARX, K. (1894) O processo global da produção capitalista. In: O capital. (Crítica da economia política). Trad. Reginaldo Sant'Anna. 3. ed., Rio de Janeiro: Civilização Brasileira, 1981. Livro Terceiro, Vol. VI.

MARX, K.; ENGELS, F. A ideologia alemã. Introdução de Jacob Gorender. Tradução de Luís Cláudio de Castro e Costa. São Paulo: Martins Fontes, 1998. 1a Edição publicada na íntegra: 1933.

MEMÓRIAS REVELADAS. Relatório anual do Centro de Referência das Lutas Políticas no Brasil (1964-1985) - Memórias Reveladas. Rio de Janeiro: Arquivo Nacional, 2009. Mimeo.

. Relatório Síntese de 5 anos de atividades do Memórias Reveladas. Rio de Janeiro: Arquivo Nacional, 2014. Mimeo.

. BANCO DE DADOS. Disponível em: < http: //www.memoriasreve ladas.gov.br.>. Acesso em: 27 jul. 2012.

MEZAROBBA, G. Um acerto de contas com o futuro. A anistia e suas consequências: um estudo do caso brasileiro. Dissertação de mestrado. Programa de Pós-Graduação em Ciência Política - FFLCH/USP, SP, 2009.

ORGANIZAÇÃO DAS NAÇÕES UNIDAS (ONU). Questions of impunity of perpetrators of human rights violations. 1997. Disponível em: <http:// www.unhcr.org/refworld/docid/3b00f1a124.html>. Acesso em: 14 jan. 2012. 


\section{Revista pll paUtg}

\} MEMÓRIAS REVELADAS - STAMPA, I.; RODRIGUES, V. \}

ORGANIZAÇÃO DAS NAÇÕES UNIDAS (ONU). The rule of law and transitional justice in conflict and post-conflict societies. New York: Report of the Secretary-General to the Security Council, 2004. Disponível em: <http:/ /www.un.org/en/ruleoflaw/index.shtml>. Acesso em: 05 set. 2012.

SALES, J. R. Ditadura militar, anistia e a construção da memória social. In: SILVA, H. R. K. A luta pela anistia. São Paulo: Imprensa Oficial, 2009.

SECRETARIA DE DIREITOS HUMANOS/PR. Direitos Humanos: percepções da opinião pública. VENTURI, G. (Org.). 1ae edição. Brasília: SDH/PR, 2010. . Portaria $n^{\circ} 21$ da SEDH/PR, de 21 de fevereiro de 2005. Mimeo.

SILVA, J. A. O Centro de Referência das Lutas Políticas no Brasil (19641985): Memórias Reveladas. Acervo - Revista do Arquivo Nacional, dossiê Arquivos do regime militar, vol. 21, no 02, jul/dez 2008.

. Entrevista a Vicente Rodrigues. Rio de Janeiro, dezembro de 2012.

SILVA, F. C. T. Crise da ditadura militar e o processo de abertura política. In: FERREIRA, J.; DELGADO, L. A. N. (Org.). O Brasil Republicano. Vol. 4: O tempo da ditadura. Regime militar e movimentos sociais em fins do século XX. Rio de Janeiro: Civilização Brasileira, 2003.

SILVA FILHO, J. C. M. Dever de memória e a construção da história viva: a atuação da Comissão de Anistia do Brasil na concretização do direito à memória e à verdade. In: PADRÓS, E. S. et al (Org.). A ditadura de segurança nacional no Rio Grande do Sul (1964-1985): história e memória. v. 4. Porto Alegre: Corag, 2009.

SOARES, I. V. Justiça de Transição. Verbete. In: Dicionário de Direitos Humanos. Brasília: Escola Superior do Ministério Público da União, 2010. Disponível em: <http://www.esmpu.gov.br/dicionario/tiki-index.php>. Acesso em: 18 nov. 2012.

STAMPA, I. T. Memórias Reveladas e os arquivos do período da ditadura militar. Revista Com Ciência. Campinas: SBPC/Labjor, abril de 2011. Disponível em: <http://www.comciencia.br/comciencia/?section=8\&edicao=65 \&id=825 >. Acesso em: 14 jan. 2012.

TEITEL, R. Genealogia da Justiça Transicional. In: REÁTEGUI, F. (Org). Justiça de Transição - manual para a América Latina. Brasília: Ministério da Justiça; Nova York: ICTJ, 2011.

VAN ZYL, P. Promovendo a justiça transicional em sociedades pós-conflito. In: REÁTEGUI, F. (Org.). Justiça de Transição: manual para a América Latina. Brasília: Ministério da Justiça; Nova York: ICTJ, 2011.

Recebido em 17 de junho de 2014.

Aprovado para publicação em 20 de junho de 2014. 